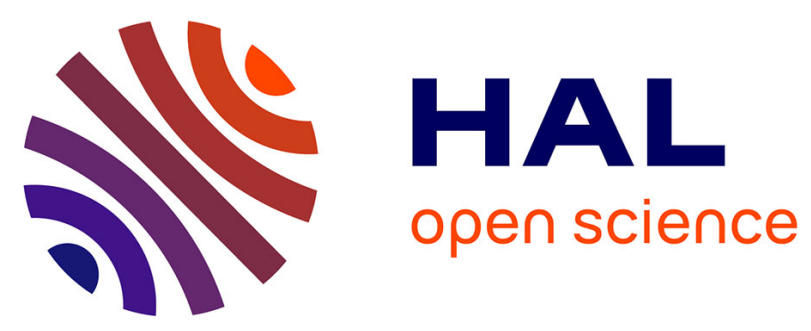

\title{
Transactional sex among men who have sex with men in the French Antilles and French Guiana: frequency and associated factors
}

\author{
Justine Klingelschmidt, Marie-Claire Parriault, Astrid van Melle, Célia
} Basurko, Barbara Gontier, André Cabié, Bruno Hoen, Marie-Thérèse Sow, Mathieu Nacher

\section{To cite this version:}

Justine Klingelschmidt, Marie-Claire Parriault, Astrid van Melle, Célia Basurko, Barbara Gontier, et al.. Transactional sex among men who have sex with men in the French Antilles and French Guiana: frequency and associated factors. AIDS Care, 2016, Epub ahead of print. 10.1080/09540121.2016.1234680 . inserm-01407263

\section{HAL Id: inserm-01407263 https://www.hal.inserm.fr/inserm-01407263}

Submitted on 1 Dec 2016

HAL is a multi-disciplinary open access archive for the deposit and dissemination of scientific research documents, whether they are published or not. The documents may come from teaching and research institutions in France or abroad, or from public or private research centers.
L'archive ouverte pluridisciplinaire HAL, est destinée au dépôt et à la diffusion de documents scientifiques de niveau recherche, publiés ou non, émanant des établissements d'enseignement et de recherche français ou étrangers, des laboratoires publics ou privés. 


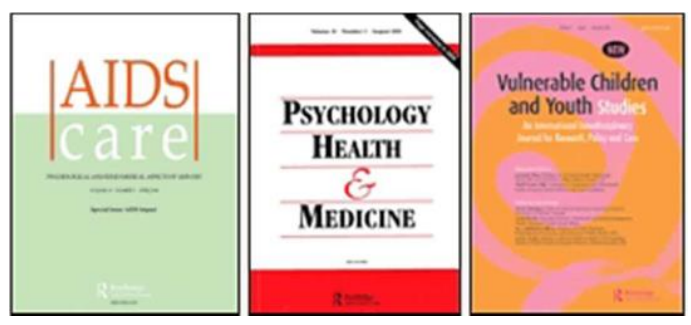

\section{Transactional sex among men who have sex with men in the French Antilles and French Guiana: frequency and associated factors}

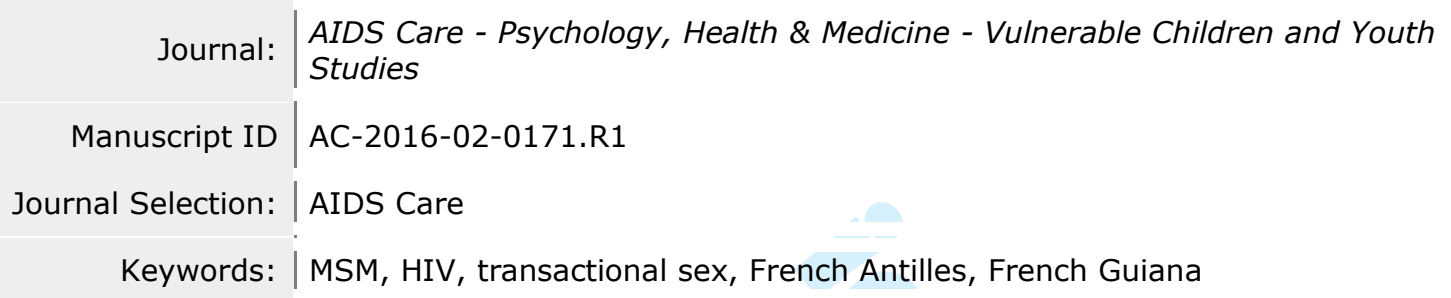


Transactional sex among men who have sex with men in the French Antilles and French Guiana: frequency and associated factors 


\section{Acknowledgment}

The KABP MSM study is part of the project "Mise en place d'un Observatoire Intercaribéen du VIH" supported by the University Medical Center of Guadeloupe.

\section{Funding}

The KABP MSM study was supported by the European INTERREG Caribbean IV Fund, by Cayenne General Hospital and the University Medical Center of Guadeloupe.

\section{Disclosure of Potential Conflicts of Interest}

No potential conflicts of interest were disclosed.

\section{Abstract}

The French Antilles (Martinique, Saint Martin, Guadeloupe) and French Guiana are the French territories most affected by the HIV epidemic. Some population groups such as men who have sex with men (MSM), especially those involved in transactional sex, are thought to be particularly vulnerable to HIV but few data exist to help characterize their health-related needs and thus implement relevant prevention interventions.

To fill this knowledge gap, we used data collected from an HIV/AIDS Knowledge, Attitudes, Behaviours and Practices survey conducted in 2012 among MSM living in the French Antilles and French Guiana and recruited through snowball sampling. Our objectives were to compare social and demographic characteristics and sexual behaviours between MSM engaging in transactional sex and MSM not engaging in transactional sex and to identify factors associated with transactional sex involvement using a logistic regression model

A total of 733 MSM were interviewed, $21 \%$ of whom reported to undergo transactional sex. Their behaviour and social and demographic characteristics were different from other MSMs' and they were more exposed to factors that are recognized to potentiate HIV vulnerability, at the individual, community, network, and structural levels. The variables positively associated with sex trade involvement were having ever consumed drug $(\mathrm{OR}=2.84$ [1.23-6.52]; $p=0.002)$, having a greater number of sex partners than the median $(\mathrm{OR}=8.31[4.84-14.30] ; p<0.001)$, having experienced intimate partner violence $(\mathrm{OR}=1.72[0.99-3.00] ; p=0.053)$, and having undergone physical aggression because of sexual orientation $(\mathrm{OR}=2.84$ [1.23-6.52]; $p=0.014)$. Variables negatively associated with sex trade 
involvement were being older $(\mathrm{OR}=0.93$ [0.90-0.97] per year; $\mathrm{p}=0.001)$, having a stable administrative situation $(\mathrm{OR}=0.10[0.06-0.19] ; \mathrm{p}<0.001)$, having a stable housing $(\mathrm{OR}=0.29[0.15-0.55] ; \mathrm{p}<0.001)$ and being employed fulltime $(\mathrm{OR}=0.29[1.23-6.52] ; \mathrm{p}=0.002)$.

\section{Keywords}

Men who have sex with men, HIV, transactional sex, French Antilles and French Guiana.

\section{Introduction}

The French Antilles (Martinique, Saint Martin, Guadeloupe) are located in the Caribbean, the region with the highest HIV prevalence after Sub-Saharan Africa. Although it is lower than in other states of the region, HIV incidence is much higher than in mainland France, reaching 59/100 000 PY in 2009-2010 for the three French Departments of America (French Guiana, Guadeloupe, Martinique), versus 17/100 000 in mainland France (Le Vu et al., 2010). In all settings where they have been studied, men who have sex with men (MSM) are disproportionately impacted by HIV compared to other heterosexual groups (S. D. Baral et al., 2015; Beyrer et al., 2012). Beyrer et al. did a comprehensive review of available data for HIV prevalence and found that it reached $25,4 \%$ in the MSM population of the Caribbean (Beyrer et al., 2012).

In mainland France, self-declared HIV prevalence varies between $12 \%$ and $15 \%$ according to the Presse Gay and Baromètre Gay studies (Velter, Bouyssou-Michel, de Busscher, Jauffret-Roustide, \& Semaille, 2007; Velter, Bouyssou-Michel, Pillonel, Jacquier, \& Semaille, 2006). The Prevagay study conducted among MSM attending commercial gay venues in Paris showed that HIV seroprevalence was $18 \%$ and highlighted that $20 \%$ of MSM were unaware of their HIV positive status (Le Vu et al., 2012). Le Vu et al.further showed that in 2008, incidence in MSM was of 1006 per 100000 person-years. While overall HIV incidence decreased in the period between 2003 and 2008 it remained high and stable among MSM (Beyrer et al., 2012). In the French Departments of America, incidence is estimated at around 1000 per 100 000, 28 times higher than in heterosexual men (Le Vu et al., 2010).

Public health research has typically treated the MSM population as a relatively homogenous group. However, some studies indicate that levels of exposure to HIV vary among MSM. In particular, MSM engaging in transactional sex - 
those who exchange sex for drugs or money- are thought to be at increased risk towards HIV acquisition and transmission.

Various studies have shown that transactional sex was associated with increased vulnerability to HIV among women but, compared to this substantial body of research, information on men who trade sex remains sparse. Recently, a meta-analysis of 33 studies from 17 countries compared HIV prevalence among MSM who engaged in transactional sex (MSM-TS) to those who did not (MSM-NTS) (Oldenburg, Perez-Brumer, Reisner, \& Mimiaga, 2015). Results showed that engagement in transactional sex was associated with a significant elevation in HIV prevalence $(\mathrm{OR}=1.34$, $95 \% \mathrm{CI}=1.11-1.62)$, notably in Latin America ( $\mathrm{OR}=2.28,95 \% \mathrm{CI}=1.87-2.78)$. The increased vulnerability to HIV associated with transactionnal sex is thought to be the result of multi-level factors, intervening at the individual level (high number of sexual partners, inconsistent condom use, psychological distress, substance use) but also at the structural level (socio-economic precariousness, limited access to healthcare and rights, multi-layered stigma) (S. D. Baral et al., 2015; Beyrer et al., 2012).

To our knowledge, few, if any, have studied the factors associated with HIV risk among the MSM population in the French Antilles and French Guiana, where homosexual behaviours are stigmatized even more than in mainland France (Halfen \& Lydié, 2014).

To fill this knowledge gap, a KAPB (Knowledge, Attitudes, Practices and Behaviours) study on HIV and STIs was conducted in 2012 among MSM in the French Antilles and French Guiana by the CIC (Clinical Investigation Center) Antilles-Guyane a single INSERM structure that bridges Guadeloupe, Martinique and French Guiana.

Data collected were then analysed to explore HIV vulnerability of MSM engaged in transactional sex in order to better target prevention interventions.

The objectives were to compare socio demographic characteristics and sexual behaviours between MSM-TS and MSM-NTS using the analytical tool developed by Baral et al.(S. Baral, Logie, Grosso, Wirtz, \& Beyrer, 2013)and to identify factors associated with transactional sex involvement.

\section{Methods}

\section{Participants and Procedures}

MSM were considered eligible to participate in the study if they were 18 years of age or older, had engaged in anal and/or oral sex with another male in the 12 months preceding the survey, and had provided written informed consent 
Given that MSM represent a hidden population with no available sampling frame, snowball sampling, a nonprobabilistic method was used to recruit participants (Heckathorn, 2011). The interviewers first had to identify and recruit a few members of the MSM population that fulfilled the study's inclusion criteria. These individuals referred to as "seeds" had to be diverse in terms of social and demographic characteristics. They participated in the survey and, at the end of the interview; these "seeds" were asked to refer one MSM from their social network. This process was repeated until the targeted sample size was reached. Appointments were made so that the individuals who accepted to take part in the study could choose when and where they wanted to be interviewed. The interviews were mainly carried out in private spaces (the participant's homes). They were conducted face-to-face by trained and multilingual interviewers familiar with the MSM population after the eligibility criteria were verified and informed written consent was obtained.

After the interview, which took from 40 to 60 minutes to complete, participants received an HIV prevention kit containing documentation on HIV/AIDS, male condoms and food vouchers.

The study was conducted in partnership with the Regional Coordination for the Fight against HIV and NGOs working with MSM (AIDES, ADER, Entr'Aides, Mama Bobi, An NouAllé, Rainbow Gwada, Paroles autour de la Santé). It was funded by the European INTERREG Caribbean IV Fund, by the Hospital of Cayenne and the University Hospital of Pointe-à-Pitre. Study procedures were reviewed and approved by the Comité Consultatif sur le Traitement de l'Information en matière de Recherche dans le domaine de la Santé (CCTIRS $n^{\circ} 12.080$ ), the Comité d'Evaluation Ethique de l'Inserm (CEEI $\mathrm{n}^{\circ}$ 12-055) and the Commission Nationale Informatique et Liberté $\left(\mathrm{CNIL} \mathrm{n}^{\circ}\right.$ DR-2012264).

\section{Study Instrument}

The anonymous questionnaire used in the study was adapted from internationally validated Behavioural Surveillance Surveys and modified for local context with the help of non-governmental associations (NGOs). It was translated into five languages (French, Spanish, English, Portuguese, and Haitian Creole) and consisted of 115 questions exploring socio demographic characteristics, sexual history and behaviour with different types of partners (regular, commercial and occasional), and knowledge, opinions and attitudes towards HIV/AIDS. 
Transactional sex involvement was based on two questions "Think about the commercial partners (partners with whom you bought or sold sex in exchange for money, services, goods and drugs you had in the previous month). In total how many were partners to whom you sold sex in exchange for money or drugs?». The second question used to construct the variable was "what is your main source of money/income at the moment?", sex work being one of the modalities. MSM were considered involved in transactional sex if they had exchanged sex for money or goods at least with one partner in the previous month or it they had declared sex work as their primary source of income."

Independent variables included socio demographic characteristics such as age, nationality, administrative status, housing status, sexual behaviours. For the "nationality" variable, a "Caribbean" category was created, including the individuals from the Dominican Republic, Haiti, Dominica or St Lucia. Individuals who declared having ever tried marijuana, crack or another drug were considered as "having ever consumed drugs".

Stable administrative status was defined as having French nationality or having a long-term (10 years) residence permit, whereas the individuals without residence permit, with a short-term residence permit ( 3 months or 1 year) or asylum seekers were considered as having an "unstable administrative status". Stable housing included individuals living in their own personal/familial house, in a rented house/apartment, or in social housing. People living in shared apartments, in informal settlements, on the streets, in a squat, and homeless people were included in the "unstable housing" category. A participant was considered as having undergone intimate partner violence if he had ever been humiliated, threatened, injured or insulted by a partner.

Sexual history and behaviour (notably condom use) with different types of partners was explored: regular partners were those with whom the participant "had sex for six months at least", commercial partners were those with whom the participant "bought or sold sex in exchange for money, services, goods or drugs" and occasional partners were those who were not regular partners nor commercial ones."

\section{Statistical Analysis}

First, a descriptive analysis was conducted to compare socio-demographic characteristics and sexual behaviours between 2 groups: MSM involved in transactional sex (MSM-TS) and MSM not involved in transactional sex (MSMNTS). Mean and standard deviation for normally distributed variables, and frequencies and percentages for qualitative variables were calculated.

Categorical variables were compared between groups using Pearson's $\chi^{2}$ test or Fisher's exact test when appropriate. Comparisons of continuous variables were carried out using Student's t-test. Results of the descriptive analysis were 
framed with the modified social ecological model, a flexible analytical tool developed by Baral et al.(S. Baral et al., 2013) to guide the assessment of multi-level drivers of HIV infection risk.

Then, univariate and multivariate logistic regression analysis were performed to identify factors associated with transactional sex involvement. Given the large number of variables, the selection of independent variables for the multivariate model retained biographically pertinent variables and variables with a $\mathrm{p}<0.05$ in univariate logistic regression. To obtain the final multivariate model, a backwards elimination procedure was used. All candidate variables were entered in the model, they were then removed one by one starting with the variable with the largest $\mathrm{p}$ value until all variables in the model are p<0.05.A "missing data" category containing missing data and "does not know/no response" was created for each variable to avoid losing observations, and thus statistical power in the final multivariate model.

Analyses were conducted with Stata 13.0 (StataCorp, College Station,TX)

\section{Results}

\section{Overall sample description}

The final sample size consisted of 733 persons recruited and interviewed in the main cities of the four different sites: 344 were interviewed in Martinique, 223 in French Guiana, 124 in Guadeloupe, and 42 in Saint-Martin. Transgender people were also interviewed, but they were excluded in the present analysis and will be analyzed elsewhere.

The median age was 29 years $([\mathrm{IQR}]=24-37)$. Among the 733 MSM who completed the survey, 153 (20.8\%) were involved in transactional sex (MSM-TS). Their characteristics were compared with those of MSM not involved in transactional sex (MSM-NTS).

\section{Comparisons between MSM involved in transactional sex (MSM-TS) and other MSM (MSM-NTS)}

Comparisons revealed significant differences with respect to socio demographic characteristics and sexual behaviours between the two groups. MSM-TS were more likely to have been interviewed in French Guiana and Saint-Martin. They were also younger $(27$ years vs 32 years, $\mathrm{p}<0.001)$ and less likely to have French nationality. Table 1 shows that unstable administrative situation was common among male involved in transactional sex $(60.1 \%$ vs $12 \%$, p<0.001), as well as unstable housing (48.4\% vs $14.3 \%$, p<0.001). Only a small proportion of male involved in transactional sex
were
employed
full-time
$(11.8 \%$
VS
$60.7 \%$
$\mathrm{p}<0.001)$. 
Substance use was found to be higher among MSM-TS compared with MSM-NTS. Male who engaged in transactional sex were more likely to have consumed 5 or more drinks at one occasion in the previous month (83\% vs $60 \%, \mathrm{p}<0.001)$. At last sexual intercourse with casual partner, $80.7 \%$ of male who reported transactional sex had consumed alcohol, vs $48.1 \%$ in the other group $(\mathrm{p}<0.001)$. However, no significant difference was found for drug consumption history (having ever tried marijuana, or crack, or another drug) between the two groups.

Our results outlined differences in reported condom use between MSM-TS and MSM-NTS. Male involved in transactional sex were significantly more likely to have used a condom at last sexual intercourse, and to report systematic condom use with the regular partner. However, no significant difference was found between MSM-TS and MSM-NTS regarding frequency of condom use with the occasional and commercial partner: the proportion of individuals never using a condom, or using it only "sometimes" were high in both groups. One of the reasons why MSM-TS had not used a condom during their last commercial intercourse was because "the client had paid more for it".

Our results also highlighted the substantially high level of violence experienced by males involved in transactional sex: $40 \%$ of them had experienced intimate partner violence (vs $22.9 \%$ in MSM-NTS, p<0.001). Additionally, males involved in transactional sex were also more likely to have been injured or insulted due to their sexual orientation.

\section{Multivariate analysis}

Table 2 shows the results of the logistic regression analysis of independent factors associated with transactional sex involvement. The variables positively associated with sex trade involvement were having ever consumed drug $(\mathrm{OR}=2.84[1.23-6.52] ; p=0.002)$, having a greater number of sex partners than the median $(\mathrm{OR}=8.31$ [4.84-14.30] ; $p<0.001)$, having experienced intimate partner violence ( $\mathrm{OR}=1.72[0.99-3.00] ; p=0.053)$, and having undergone physical aggression because of sexual orientation $(\mathrm{OR}=2.84[1.23-6.52] ; p=0.014)$. Variables negatively associated with sex trade involvement were being older $(\mathrm{OR}=0.93$ [0.90-0.97] per year; $\mathrm{p}=0.001)$, having a stable administrative situation $(\mathrm{OR}=0.10[0.06-0.19] ; \mathrm{p}<0.001)$, having a stable housing $(\mathrm{OR}=0.29[0.15-0.55] ; \mathrm{p}<0.001)$ and being employed full-time $(\mathrm{OR}=0.29[1.23-6.52] ; \mathrm{p}=0.002)$.

\section{Discussion}


Baral et al. conceptualized a theoretical framework -the modified social ecological model- to characterize and analyze multiple levels of HIV risks among vulnerable populations (S. Baral et al., 2013). Five levels of risks are included: individual, network, community, policy and stage of the HIV epidemic. The HIV epidemic among MSM is driven by a complex set of factors at multiple levels, including individual, social and structural factors. Accordingly, Baral's model appeared a relevant conceptual framework to analyze multi-level vulnerability to HIV in the subpopulation of MSM involved in transactional sex.

Individual level factors refer to biologic or behaviours associated with higher vulnerability to acquire or transmit HIV. Our results showed inconsistent condom use among MSM-TS as well as MSM-NTS. Notably, $33.6 \%$ of MSM-TS did not systematically use condom with their commercial partners. A focus on the underlying reasons why MSM-TS had not used a condom during their last commercial intercourse showed that this was because "the client had paid more for it". Non-use of condom because of client offering additional money has been reported by various studies among male sex workers (Lau, Cai, Tsui, Chen, \& Cheng, 2009; Reisner, Mimiaga, Mayer, Tinsley, \& Safren, 2008). Our results outlined higher substance consumption in MSM-TS than in other MSM. In the literature, alcohol use before or during sex is associated with increased sexual risk behaviour such as increased risk of unprotected anal intercourse (Lane, Shade, McIntyre, \& Morin, 2008) and decreased ability to negotiate protection measures (Liu \& Detels, 2012).

Network level factors include the characteristics of sexual networks like their size or density. In our sample, the mean number of partners in MSM-TS was five times higher than other MSM. Large sexual networks have been associated with unprotected anal intercourse (Choi, Gibson, Han, \& Guo, 2004; Choi, McFarland, et al., 2004) and provide increased probability to be exposed to HIV positive potential partners (Smith, Grierson, Wain, Pitts, \& Pattison, 2004).

Community - related factors analysis underlined that MSM-TS were more frequently victims of violence than MSMNTS. In the French Antilles and French Guiana, same sex practices are not criminalized as in many Caribbean countries, but homosexuality remains highly stigmatized (Halfen \& Lydié, 2014), more so than in mainland France. Various studies have shown that homophobic violence is associated with deleterious mental health outcomes such as psychological distress and depression (Mills et al., 2004) and lower self-esteem and increased suicidal ideation (Huebner, Rebchook, \& Kegeles, 2004). Homophobia also affects MSM's vulnerability to HIV in an indirect way : some studies suggest that the experience of discrimination and stigma associated with sexual orientation is strongly associated with fear of seeking health care services (Fay et al., 2011) and may act as a barrier to HIV testing (Pyun et al., 2014). 
Structural factors linked to HIV vulnerability should take into account the high proportion of MSM-TS having unstable administrative situations, with no or short-term residence permit. This may prevent them from accessing the legal employment market and could thus lead them to engage in transactional sex. Unstable administrative situations may also increase HIV vulnerability because it further complicates access to healthcare and prevention (Bourdier, 2002). Any undocumented migrant with limited resources living in France for at least three months may be eligible for State Medical Assistance (Aide Médicale d'Etat), a program covering health care expenses. However, in practice, only some of them have access to it. In the French Antilles and French Guiana, especially in French Guiana, a few studies have highlighted administrative practices that restrict access to healthcare and rights (request for abusive supporting documentation, loss of files, excessive delays, etc.) (Carde, 2011; Jolivet, 2014).

Finally, all these factors linked to HIV vulnerability should be interpreted within the context of the disproportionately high burden of HIV affecting MSM when compared to other population groups: in such an active epidemic context, any high- risk practice may have important epidemiological repercussions.

We further wanted to determine factors associated with engagement in transactional sex. Prior research has shown that young age, homelessness, regular and heavier use of alcohol and unemployment (Bobashev, Zule, Osilla, Kline, \& Wechsberg, 2009; Oldenburg, Perez-Brumer, Biello, et al., 2015; Weber et al., 2001) were independently associated with trading sex for money, drugs, housing or other goods. Our final multivariate model is consistent with these results, and reveals a profile of MSM-TS characterized by multidimensional precariousness, substance use and being the victim of violence.

Some limitations and biases should be taken into account when interpreting our results. The questionnaire was designed to assess the Knowledge, Attitudes and Practices towards HIV and STIs, not to specifically explore the issue of transactional sex. Therefore the analysis was lacking elements that may have provided some useful information such as frequency of sex trade, age at first commercial intercourse, or reasons for engaging in the sex trade.

In this study, MSM were recruited through snowball sampling. This method was chosen because it was adapted to hidden populations such as MSM (Heckathorn, 2011) and it was the best alternative given the human, financial and time resources of the project team. Selection biases may occur because people with large social networks have a greater probability to be sampled. To minimize this bias, interviewers who knew the MSM population were employed, and they had to recruit "seeds"(initial recruits) with contrasted characteristics. However, despite these efforts, 
snowball sampling remains a non-probabilistic method and as such, it makes the extrapolation of the findings to the broader MSM population from the French Antilles and French Guiana questionable.

Given the declarative nature of the data and face to face interviews, our data may also be subject to social desirability bias and thus sexual risk behaviours may have been underreported. However, the investigators were all close to the field, coming from NGOs or involved with the MSM population possibly minimizing this bias.

Finally, it is worth mentioning that since the study was cross-sectional, statistically significant relationships between sex trade involvement and the explanatory factors cannot be interpreted in terms of causality.

Despite these limitations and biases, this study remains the first to focus on the MSM population of the French Antilles and French Guiana. Our results highlighted some interesting points that may help optimizing prevention interventions for this at-risk subgroup of MSM. For instance, substance consumption or fighting against homophobia are potential priority targets that should be specifically addressed for increased impact.

However, it is worth reminding that MSM involved in transactional sex are not a homogenous group, and any prevention program will require further discussion with local actors (NGOs, health professionals, etc.) to be adapted to the diversity of social, economic and cultural contexts.

\section{Conclusion}

Transactional sex among females is a well-known prevention priority; MSM is also another well identified vulnerable group worldwide. However, MSM who sell sex are currently a blind spot of prevention programmes. Our results show a high proportion of MSM were involved in transactional sex with social vulnerabilities and high-risk practices that require specific attention. HIV prevention interventions should not only target individual factors but also the social context in which male involved in transactional sex live, as well as their sexual networks and their community environment. Recently, France approved free pre-exposure prophylaxis (PrEP) via a Recommendation of Temporary Use (RTU). Such antiretroviral-based prevention approaches could be relevant at the individual level: in a context of low condom use, it would give MSM engaging in high risk transactional sex an alternative to control their HIV risk. At a community and structural level, interventions that alleviate background vulnerability factors (fight against homophobia, access to rights and healthcare) should be reinforced.

\section{Table 1: Comparative Analysis}




\section{Health Sciences}

No transactional sex

$(n=580)$

$\mathrm{n}(\%)$

Nationality $(n=733)$

French

Guyanese/Surinam ese

"Caribbean"

Brazilian

Other

Stable administrative situation $(n=733)$

No $70(12,1)$

Yes

$510(87,9)$

Stable housing $(n=733)$

No $\quad 83(14,3)$

Yes

$497(85,7)$

Full-time employment $(n=733)$

No

Yes

Condom at last anal sex $(n=709)$

No

Yes

Condom use frequency with regular partner $(n=562)$

Never

Every time

$228(39,3)$

$352(60,7)$

$184(32,9)$

$376(67,1)$

$163(34,8)$

$160(34,2)$

$145(40,0)$

Sometimes

)

Condom use frequency with occasionnal partner $(n=376)$

$\begin{array}{lll}\text { Never } & 12(3,8) & 4(7,0) \\ \text { Every time } & 232(72,7) & 36(63,2) \\ \text { Sometimes } & 75(23,5) & 17(29,8)\end{array}$

Condom use frequency with commercial partner $(n=201)$

$\begin{array}{lcc}\text { Never } & 0 & 5(3,4) \\ \text { Every time } & 32(61,5) * & 99(66,4) \\ \text { Sometimes } & 20(38,5) * & 45(30,2)\end{array}$

Important alcohol consumption ( $<5$ drinks on one occasion) ( $n=733$ )

No $232(40,0)$

Yes $\quad 348(60,0)$

Drug consumption history $(n=733)$

No

$500(86,2)$

$80(13,8)$

$26(17,0)$

Yes

Alcohol consumption at last intercourse with commercial partner $(n=190)$

$\begin{array}{lll}\text { No } & 22(47,8) & 69(47,9) \\ \text { Yes } & 24(52,2) & 75(52,1)\end{array}$

Alcohol consumption at last intercourse with casual partner $(n=354)$

No $154(51,9)$

$11(19,3)$

Yes

$143(48,1)$

$46(80,7)$

Intimate partner violence $(n=704)$

$\begin{array}{lll}\text { No } & 430(77,1) & 88(60,3) \\ \text { Yes } & 128(22,9) & 58(39,7)\end{array}$

Has previously been insulted because of sexual orientation ( $n=722)$

$\begin{array}{lll}\text { No } & 434(76,0) & 97(64,2) \\ \text { Yes } & 137(24,0) & 54(35,8)\end{array}$

Has previously been physically assaulted because of sexual orientation $(n=716)$

\begin{tabular}{|c|c|c|c|}
\hline No & $536(94,7)$ & $123(82,0)$ & $<0,001$ \\
\hline Yes & $30(5,3)$ & $27(18,0)$ & \\
\hline
\end{tabular}

† p calculated with $x 2$ Test or Fisher's exact Test for qualitative variables, Student's Test for quantitative variables

* individuals included in this category are those who reported having paid for sex (commercial sex as clients)

http://mc.manuscriptcentral.com/ac-phm-vcy
$<0,001$

Page 12 of 27

$p$-value $†$

$<0,001$

$<0,001$

$<0,001$

$<0,001$

0,007 
Table 2 : Multivariate Analysis

\begin{tabular}{|c|c|c|c|c|c|}
\hline & $\begin{array}{c}\text { No transactional sex } \\
\mathbf{n}=580 \\
\mathrm{n}(\%) \\
\end{array}$ & $\begin{array}{c}\text { Transactional sex } \\
\mathbf{n}=\mathbf{1 5 3} \\
\mathrm{n}(\%) \\
\end{array}$ & $\begin{array}{c}\text { Univariate Analys is } \$ \\
\text { Crude Odds Ratio }[\mathrm{Cl} 95 \%] \dagger\end{array}$ & $\begin{array}{c}\text { Multivariate Analys is } £ \\
\text { Adj. Odds Ratio [IC 95\%]† }\end{array}$ & p adj. \\
\hline \multicolumn{6}{|l|}{ Age $(n=730)$} \\
\hline \multicolumn{6}{|l|}{ [mean +/- standard deviation] } \\
\hline Mean & {$[32,0+/-9,9]$} & {$[27,1+/-6,1]$} & $0,93[0,91-0,96]$ & $0,93[0,90-0,97]$ & 0,001 \\
\hline \multicolumn{6}{|c|}{ Stable administrative situation ( $n=733$ ) } \\
\hline No & $70(12,1)$ & $92(60,1)$ & 1 & 1 & I \\
\hline Yes & $510(87,9)$ & $61(39,9)$ & $0,09[0,06-0,14]$ & $0,10[0,06-0,19]$ & $<0,001$ \\
\hline \multicolumn{6}{|l|}{ Stable housing ( $n=733)$} \\
\hline No & $83(14,3)$ & $74(48,4)$ & 1 & 1 & I \\
\hline Yes & $497(85,7)$ & $79(51,6)$ & $0,17[0,12-0,26]$ & $0,52[0,30-0,89]$ & 0,018 \\
\hline \multicolumn{6}{|l|}{ Full-time employment ( $n=733)$} \\
\hline No & $228(39,3)$ & $135(88,24)$ & 1 & 1 & 1 \\
\hline Yes & $352(60,7)$ & $18(11,76)$ & $0,08[0,05-0,15]$ & $0,29[0,15-0,55]$ & $<0,001$ \\
\hline \multicolumn{6}{|l|}{ Drug consumption history $(n=733)$} \\
\hline No & $500(86,2)$ & $124(81,0)$ & 1 & 1 & 1 \\
\hline Yes & $80(13,8)$ & $29(19,0)$ & $1,46[0,92-2,33]$ & $2,84[1,23-6,52]$ & 0,002 \\
\hline \multicolumn{6}{|c|}{ Number of partners relative to the median $(n=733)$} \\
\hline Lower or equal to the median & $372(64,1)$ & $34(22,2)$ & 1 & 1 & 1 \\
\hline Above the median & $178(30,7)$ & $115(75,2)$ & $7,07[4,63-10,78]$ & $8,31[4,84-14,30]$ & $<0,001$ \\
\hline$N D$ * & $30(5,2)$ & $4(2,6)$ & $1,46[0,49-4,39]$ & $1,20[0,33-4,37]$ & 0,774 \\
\hline \multicolumn{6}{|l|}{ Intimate partner violence $(n=704)$} \\
\hline No & $430(74,1)$ & $88(57,5)$ & 1 & 1 & 1 \\
\hline Yes & $128(22,1)$ & $58(37,9)$ & $2,21[1,51-3,26]$ & $1,72[0,99-3,00]$ & 0,053 \\
\hline ND * & $22(3,8)$ & $7(4,6)$ & $1,55[0,64-3,75]$ & $3,57[1,15-11,14]$ & 0,028 \\
\hline \multicolumn{6}{|c|}{ Has been previously physically assaulted because of sexual orientation ( $n=733$ ) } \\
\hline $\mathrm{Np}$ & $536(92,4)$ & $123(80,4)$ & 1 & 1 & 1 \\
\hline Yes & $30(5,2)$ & $27(17,6)$ & $3,92[2,25-6,84]$ & $2,84[1,23-6,52]$ & 0,014 \\
\hline $\mathrm{ND}^{*}$ & $14(2,4)$ & $3(2,0)$ & $0,93[0,26-3,30]$ & $1,03[0,16-6,50]$ & 0,974 \\
\hline
\end{tabular}

$\S$ Univariate analysis using a logistic regression model

£ Multivariate analysis using a multivariate stepwise logistic regression

* $\mathrm{ND}=$ not documented. Includes missing data, "does not know" and "no response" terms 


\section{References}

Baral, S., Logie, C. H., Grosso, A., Wirtz, A. L., \& Beyrer, C. (2013). Modified social ecological model: a tool to guide the assessment of the risks and risk contexts of HIV epidemics. BMC Public Health, 13, 482. doi:10.1186/1471-2458-13-482

Baral, S. D., Friedman, M. R., Geibel, S., Rebe, K., Bozhinov, B., Diouf, D., . . Caceres, C. F. (2015). Male sex workers: practices, contexts, and vulnerabilities for HIV acquisition and transmission. Lancet, 385(9964), 260-273. doi:10.1016/s0140-6736(14)60801-1

Beyrer, C., Baral, S. D., van Griensven, F., Goodreau, S. M., Chariyalertsak, S., Wirtz, A. L., \& Brookmeyer, R. (2012). Global epidemiology of HIV infection in men who have sex with men. Lancet, 380(9839), 367-377. doi:10.1016/s0140-6736(12)60821-6

Bobashev, G. V., Zule, W. A., Osilla, K. C., Kline, T. L., \& Wechsberg, W. M. (2009). Transactional sex among men and women in the south at high risk for HIV and other STIs. Journal of Urban Health, 86 Suppl 1, 32-47. doi:10.1007/s11524-009-9368-1

Bourdier, F. (2002). Malades et maladies en exil : les migrations brésiliennes vers la Guyane à l'épreuve du sida. Sciences sociales et santé, 5-28. Retrieved from http://www.persee.fr/doc/sosan 02940337_2002_num_20_3_1557

Carde, E. (2011). Adapter les pratiques médicales au terrain : maternité et VIH en Guyane et à Saint-Martin. Santé Publique, 23, 441-453. Retrieved from www.cairn.info/revue-sante-publique-2011-6-page-441.htm.

Choi, K. H., Gibson, D. R., Han, L., \& Guo, Y. (2004). High levels of unprotected sex with men and women among men who have sex with men: a potential bridge of HIV transmission in Beijing, China. AIDS Education and Prevention, 16(1), 19-30.

Choi, K. H., McFarland, W., Neilands, T. B., Nguyen, S., Louie, B., Secura, G. M., . . V Valleroy, L. (2004). An opportunity for prevention: prevalence, incidence, and sexual risk for HIV among young Asian and Pacific Islander men who have sex with men, San Francisco. Sexually Transmitted Diseases, 31(8), 475-480.

Fay, H., Baral, S. D., Trapence, G., Motimedi, F., Umar, E., Iipinge, S., . . Beyrer, C. (2011). Stigma, health care access, and HIV knowledge among men who have sex with men in Malawi, Namibia, and Botswana. AIDS and Behavior, 15(6), 1088-1097. doi:10.1007/s10461-010-9861-2

Halfen, S., \& Lydié, N. (2014). Les habitants des Antilles et de la Guyane face au VIH/SIDA et à d'autres risques sexuels. Retrieved from Paris: $\quad$ http://www.inpes.sante.fr/CFESBases/catalogue/pdf/1577.pdf 
Heckathorn, D. D. (2011). Snowball versus respondent-driven sampling. Sociological Methodology, 41(1), 355-366. doi:10.1111/j.1467-9531.2011.01244.x

Huebner, D. M., Rebchook, G. M., \& Kegeles, S. M. (2004). Experiences of harassment, discrimination, and physical violence among young gay and bisexual men. American Journal of Public Health, 94(7), 1200-1203.

Jolivet, A. (2014). Migrations, santé et soins en Guyane. Université Pierre et Marie Curie - Paris VI, Paris. Retrieved from https://tel.archives-ouvertes.fr/tel-01067997/document

Lane, T., Shade, S. B., McIntyre, J., \& Morin, S. F. (2008). Alcohol and sexual risk behavior among men who have sex with men in South african township communities. AIDS and Behavior, 12(4 Suppl), S78-85. doi:10.1007/s10461-008-9389-x

Lau, J. T., Cai, W. D., Tsui, H. Y., Chen, L., \& Cheng, J. Q. (2009). Psychosocial factors in association with condom use during commercial sex among migrant male sex workers living in Shenzhen, mainland China who serve cross-border Hong Kong male clients. AIDS and Behavior, 13(5), 939-948. doi:10.1007/s10461-009-9591-5

Le Vu, S., Le Strat, Y., Barin, F., Pillonel, J., Cazein, F., Bousquet, V., . . . Desenclos, J. C. (2010). Population-based HIV-1 incidence in France, 2003-08: a modelling analysis. Lancet Infectious Diseases, 10(10), 682-687. doi:10.1016/s1473-3099(10)70167-5

Le Vu, S., Velter, A., Meyer, L., Peytavin, G., Guinard, J., Pillonel, J., . . Semaille, C. (2012). Biomarker-based HIV incidence in a community sample of men who have sex with men in Paris, France. PLoS One, 7(6), e39872. doi:10.1371/journal.pone.0039872

Liu, S., \& Detels, R. (2012). Recreational drug use: an emerging concern among venue-based male sex workers in China. Sexually Transmitted Diseases, 39(4), 251-252. doi:10.1097/OLQ.0b013e31824a0903

Mills, T. C., Paul, J., Stall, R., Pollack, L., Canchola, J., Chang, Y. J., . . . Catania, J. A. (2004). Distress and depression in men who have sex with men: the Urban Men's Health Study. American Journal of Psychiatry, 161(2), 278-285. doi:10.1176/appi.ajp.161.2.278

Oldenburg, C. E., Perez-Brumer, A. G., Biello, K. B., Landers, S. J., Rosenberger, J. G., Novak, D. S., . . Mimiaga, M. J. (2015). Transactional sex among men who have sex with men in Latin America: economic, sociodemographic, and psychosocial factors. American Journal of Public Health, 105(5), e95-e102. doi:10.2105/ajph.2014.302402

Oldenburg, C. E., Perez-Brumer, A. G., Reisner, S. L., \& Mimiaga, M. J. (2015). Transactional Sex and the HIV Epidemic Among Men Who have Sex with Men (MSM): Results From a Systematic Review and Metaanalysis. AIDS and Behavior, 19(12), 2177-2183. doi:10.1007/s10461-015-1010-5 
Pyun, T., Santos, G. M., Arreola, S., Do, T., Hebert, P., Beck, J., . . Ayala, G. (2014). Internalized homophobia and reduced HIV testing among men who have sex with men in China. Asia-Pacific Journal of Public Health,

26(2), 118-125. doi:10.1177/1010539514524434

Reisner, S. L., Mimiaga, M. J., Mayer, K. H., Tinsley, J. P., \& Safren, S. A. (2008). Tricks of the trade: sexual health behaviors, the context of HIV risk, and potential prevention intervention strategies for male sex workers. J LGBT Health Res, 4(4), 195-209.

Smith, A. M., Grierson, J., Wain, D., Pitts, M., \& Pattison, P. (2004). Associations between the sexual behaviour of men who have sex with men and the structure and composition of their social networks. Sexually Transmitted Infections, 80(6), 455-458. doi:10.1136/sti.2004.010355

Velter, A., Bouyssou-Michel, A., de Busscher, P. O., Jauffret-Roustide, M., \& Semaille, C. (2007). Enquête Presse Gay 2004. Retrieved from Saint-Maurice:

Velter, A., Bouyssou-Michel, A., Pillonel, J., Jacquier, G., \& Semaille, C. (2006). Baromètre gay 2005 : enquête auprès des hommes fréquentant les lieux de rencontre gay franciliens. Numéro thématique. Infections sexuellement transmissibles et VIH : les comportements à risque toujours d'actualité Bull Epidemiol Hebd(25), 178-180.

Weber, A. E., Craib, K. J., Chan, K., Martindale, S., Miller, M. L., Schechter, M. T., \& Hogg, R. S. (2001). Sex trade involvement and rates of human immunodeficiency virus positivity among young gay and bisexual men. International Journal of Epidemiology, 30(6), 1449-1454; discussion 1455-1446 